\title{
Case series: rituximab in the treatment of refractory sight-threatening scleritis
}

Kiki van Bilsen 1*, P Martin van Hagen ${ }^{1}$, Tom Missotten ${ }^{3}$, Seerp G Baarsma ${ }^{3}$, Robert W Kuijpers², Jan AM van Laar ${ }^{1}$

From 6th European Workshop on Immune-Mediated Inflammatory Diseases

Nice, France. 23-25 November 2011

\section{Purpose}

Scleritis is a chronic vasculitis of scleral vessels leading to a substantial amount of morbidity and even blindness. Oral steroids and intensive immunosuppressive treatments are often used to to achieve long-term control of disease. But those drugs have severe adverse effects and there is a significant number of non-responders. We describe six patients with refractory scleritis who received rituximab.

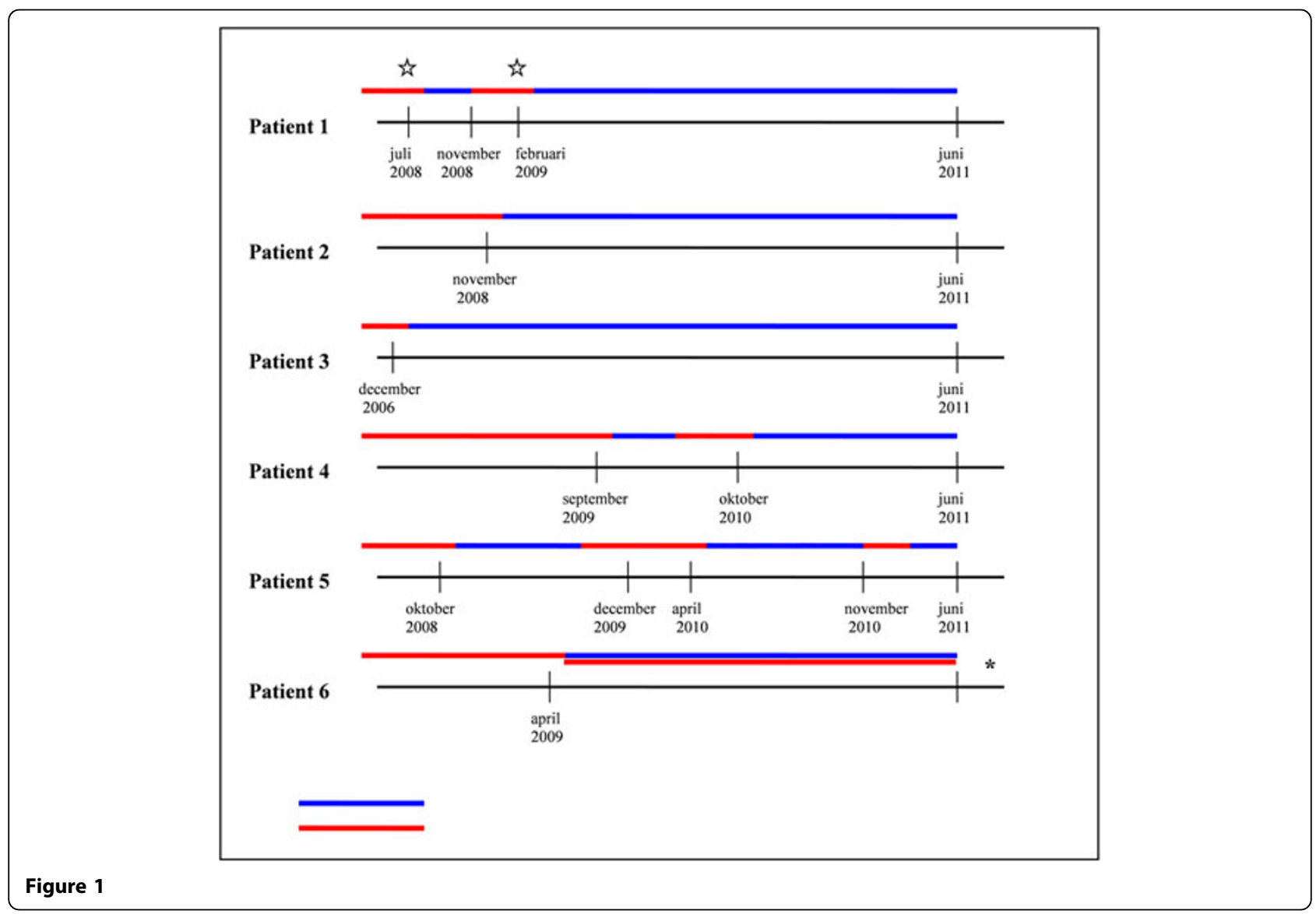

'Dept. of Internal Medicine/Clinical Immunology, Erasmus University Medical

Center, Rotterdam, The Netherlands

Full list of author information is available at the end of the article 


\section{Methods}

A case series of six patients (aged 39-66) with refractory scleritis (4 idiopathic, 2 relapsing polychondritis), including $\mathrm{B}$ cell monitoring. One treatment cycle consisted of $1000 \mathrm{mg}$ initially and $1000 \mathrm{mg}$ two week later. Prior to infusion $100 \mathrm{mg}$ methyprednisolon was administered i.v.

\section{Results}

In all patients disease activity decreased. However, in four patients symptoms returned resp. 2,4,6 and 9 months after therapy. In two cases complete remission was achieved. Two patients received a second rituximab cycle successfully. No correlation was found between B cells reoccurrence and refractory disease. [Figure 1]

\section{Conclusions}

Clinical activity of scleritis in all patients decreased after treatment. In two cases scleritis went in complete remission after one cycle of treatment. Rituximab may be a new promising therapeutic tool in the treatment of refractory scleritis. There is no correlation between relapses and B cell recovery.

\section{Author details}

'Dept. of Internal Medicine/Clinical Immunology, Erasmus University Medical Center, Rotterdam, The Netherlands. ${ }^{2}$ Dept of Opthalmology, Erasmus

University Medical Center, Rotterdam, The Netherlands. ${ }^{3}$ The Rotterdam Eye Hospital, Rotterdam, The Netherlands.

Published: 23 November 2011 